\title{
Kemoterapi Sonrası Retroperitoneal Lenf Nodu Diseksiyonu
}

\section{Postchemotherapy Retroperitoneal Lymph Node Dissection}

\author{
Dr. Burak Çıtamak, Dr. Bülent Akdoğan, Dr. Mesut Altan, Dr. Haluk Özen \\ Hacettepe Üniversitesi Tıp Fakültesi, Üroloji Anabilim Dalı, Ankara, Türkiye
}

\section{Özet}

Kemoterapi sonrası retroperitoneal lenf nodu diseksiyonu, ileri evre testis tümörlerinde fevkaladeye yaklaşan sağkalım sonuçlarına çok büyük katkıda bulunan ancak cerrahi teknik açısından üroonkoloji alanındaki en zorlu cerrahilerden birisidir. Bunun yanında, testis tümörlerinin sadece tedavisi açısından değil, evrelemesi açısından da kritiktir. Kemoterapi ihtiyacını azaltır. Çıkarılacak olan alan (template) her zaman tartışma konusu olmuş; ancak genel anlamda daha geniş template daha iyi evreleme; daha etkin tedavi ancak yüksek retrograd ejakülasyon oranlarına, daha dar modifiye rezeksiyonlar ise daha iyi hayat kalitesi ancak tümörün tam olarak rezeksiyonunda risk oluşturabilmesi açısından tartışmaları davet etmiştir. Minimal invazif yaklaşımlar, tanı açısından yeterli ancak kemoterapi verilmeksizin kür açısından problemli olabileceği için sadece deneyimli merkezlerde uygulanmalıdır. (Üroonkoloji Bülteni 2014;13:169-175)

Anahtar Kelimeler: Testis kanseri, RPLND, kemoterapi, PKRPLND

\begin{abstract}
Summary
Post-chemotherapy retroperitoneal lymph node dissection contributes most important survival results to advanced testicular cancer, however it is one of the most challenging surgeries technically in Uro-oncology. Besides, it is critical not only for treatment but also for staging of testicular cancer. It diminishes the need for chemotherapy. Boundaries of resection (template) is always a debate; wide limits may cause better staging but high rates of retrograde ejaculation, modified templates may cause better quality of life but unresected metastasis in some patients. Minimally invasive approaches are reasonable for diagnosis, although inadequate when performed without chemotherapy for cure, so they should be performed in experienced centers only. (Bulletin of Urooncology 2014;13:169-175)
\end{abstract}

Key Words: Testicular cancer, RPLND, chemotherapy, PCRPLND

\section{Giriş}

Testis tümörlerinde kemoterapi sonrası rezidüel kitlelerin cerrahi rezeksiyonu multidisipliner yaklaşımın kemoterapiyle beraber ana parçasını oluşturur. Güvenilir serum belirteçlerinin varlığı yanında, genç hasta grubunda, sisplatin tabanlı etkin kemoterapi ve iyi teknikle uygulanan RPLND ile testis kanserlerinde genel sağkalım oranları \%90'ların üzerine ulaşmıştır (1). Ancak, yaklaşık 30 yıl önce tanımlanmasına rağmen, RPLND endikasyonları hala tartışmalıdır $(2,3,4,5,6)$. Kemoterapi sonrası RPLND'nin kimlere ve nasıl yapılacağını belirleyen, primer tümörün seminom veya seminom dışı olması ve radyolojik tümör çapıdır. Şimdi bu endikasyonlarla ilgili güncel durumu literatür eşliğinde evrelere göre tek tek tartışalım.

\section{Kemoterapi Sonrası Artık Kitle Rezeksiyon Endikasyonları}

\section{Non-Seminomatöz Germ Hücreli Tümörler (NSGHT)}

Bir cm'den küçük Non-Seminomatöz Germ Hücreli Tümörler Kemoterapiden sonra tam remisyon elde edilen yani hem tümör belirteçleri normal olan hem de gösterilebilen rezidüel kitlesi olmayan NSGHT'li hastalarda cerrahiye gerek yoktur $(7,8,9)$. Ancak bu durumda olan hastalarda bile post-kemo RPLND'nin (PKRPLND) yararlarını öne çıkaran çalışmalar da vardır (3). Kemoterapi sonrası $<1$ cm kitlesi kalanlarda uzun dönem nüks oranı \%6-\%9'dur. Fakat geç relaps olan hastaların üçte birinin kaybedileceği unutulmamalıdır (10). Kemoterapi sonrası $1 \mathrm{~cm}$ 'den küçük rezidüel kitlesi olan hastalarda cerrahi hala tartışmalıdır (3). 
Kemoterapi sonrası serolojik ve radyolojik tam cevap veren ve bilgisayarlı tomografide (BT) transvers ve aksiel çapı $1 \mathrm{~cm}^{\prime}$ den küçük rezidüel kitlesi olan hastaların, tanıda International Germ Cell Cancer Collaborative Group (IGCCCG) risk kategorisine bağlı olarak \%26-\%64'ü ileri evre NSGHT'dir $(10,11)$. Bu hastalar birçok uzman tarafından relaps riski düşük olarak kabul görmüştür. Buna rağmen bazı merkezler, kemoterapi sonrası cevap ne olursa olsun kemoterapi sonrası RPLND (PC-RPLND) yapmaktadır (12). On mm'den küçük ve görüntülemede normal olarak rapor edilen lenf nodlarının yaklaşık \%30'unda teratom veya canlı tümör hücresi olduğu bildirilmektedir (13). Teratomun "benign" ismine karşın, boyuttan bağımsız olarak tam rezeksiyonu önerilmektedir. Çünkü ufak bir teartom odağı bile Growing teratoma syndrome olarak isimlendirilen ve renal obstrüksiyon, mediastinal kompresyon gibi lokal infiltratif büyümeye veya kemoterapi dirençli sarkomatöz veya nongerminal tümör transformasyonu gibi dönüşümlere neden olabilmektedir (14).

Bir cm'den küçük NSGHT'si olan ve RPLND yapılmayan hastalarda retroperitoeneal nüks oranı yaklaşık $\% 5^{\prime}$ tir $(10,11,15)$. Teratom morfolojisindeki retroperitoneal nüksler, cerrahi yapılarak tamamen ortadan kaldırılabilir (16).

Bir cm'den büyük Non-Seminomatöz Germ Hücreli Tümörler Genel kabul gören görüş, kemoterapi sonrası $1 \mathrm{~cm}$ 'den büyük rezidü kitlelerin çıkarılmasıdır $(3,8,17)$. Fakat cerrahi sınırların genişletilmiş veya modifiye olması hakkında görüş birliği yoktur.

\section{Seminomatöz Tümörler}

Seminomlarda rezidüel kitlelere yaklaşım son yıllarda oldukça değişmiştir. Birincisi, bu hastalarda ameliyat, desmoplastik reaksiyonlar nedeniyle her cerrahı ürkütecek ölçüde zordur. İkincisi, bu kitlelerde canlı tümör varlığını öngören iyi bir görüntüleme keşfedilmiştir: 18-fluoro-deoxy-glucose positron emission tomografi (FDG-PET). Bu sebeple boyuttan bağımsız olarak her kitleyi çıkarma fikri rafa kaldırılmıştır. Görüntüleme ve tümör belirteçleri ile bu karar rahatlıkla verilebilir $(18,19,20,21,22,23,24)$. FDG-PET seminoma tedavisinden sonra yüksek negatif prediktif değere sahiptir. Yanlış pozitif sonuçları azaltmak için bu görüntüleme kemoterapiden 2 ay sonra yapılmalıdır (3).

Rezidüel kitlesi $3 \mathrm{~cm}$ 'den büyük olan hastalarda canlı tümör varlığını göstermek için FDG-PET yapılmalıdır. Kitle $3 \mathrm{~cm}$ 'den küçük ise ise FDG-PET opsiyonel olarak yapılabilir (25). Kemoterapi sonrası canlı kanser yakalama oranları 3 cm'den büyük ve küçük olan kitleler için sırasıyla; \%12-\%30 ve $<\% 10$ 'dur. Rezidüel seminomatöz kitlelerde kılavuzların önerdiği sitotoksik kemoterapi protokollerinden sonra, boyut ne olursa olsun \%20 azalma beklenir $(18,26,27,28,29,30,31)$. Seminomalara yapılan PC-RPLND'lerde daha fazla intraoperatif ek girişim, daha fazla postoperatif komplikasyon oranı olduğu gösterilmiş, bu durum regrese olan kitlenin desmoplastik reaksiyonları ile ilişkili bulunmuştur. Örneğin, nefrektomi veya vasküler işlem gerekliliği seminomlarda \%38, NSGHT'de \%25 olarak gösterilmiştir (31).

European Germ Cell Cancer Consensus Group'a (EGCCCG) göre seminomlardaki artık kitlelerde kemoterapi veya radyoterapiden sonra mutlaka rezeksiyon gerekli değildir. Fakat tümör belirteçleri ve görüntüleme yöntemleriyle yakın takip gereklidir $(8,17,20,21,22)$. Birincil kemoterapi sonrası artık kitlenin büyüdüğü hastalarda ise, seminomun histolojik konfirmasyonu ve kurtarma (salvage) kemoterapisi gerekmektedir (8).

\section{Görüntüleme}

Kemoterapi sonrasında özellikle rezidüel kitlesi olan tüm hastalarda görüntüleme yöntemleri tedavi planını belirlemek için şarttır. Bu görüntüleme yöntemleri abdomen, göğüs ve pelvisi ve hatta önceki bilinen metastaz lokalizasyonlarını kapsamalıdır. BT, en kullanışlı ve en yaygın kullanılan görüntüleme yöntemidir. FDG-PET'e gelince, pozitif olması rezidüel hastalığı düşündürür, ancak prospektif çalışmalar yanlış negatifliğin teratomların tümünde, NSGHT'lerin ise yaklaşık \%40'ında saptandığını göstermektedir (32). Bu yüzden FDG-PET'in NSGHT'de yeri yoktur (33).

Retrospektif bir çalışma, metastatik seminomlu hastalarda kemoterapi sonrası 6. haftada yapılan FDG-PET ile \%82 duyarlılık ve \%90 özgüllük oranı olduğunu göstermiştir $(25,34,35)$. Rezidüel kitlesi $3 \mathrm{~cm}$ 'den büyük ve saf seminom olan hastalarda canlı tümör varlığını araştırmak için FDG-PET yapılmalıdır. FDG-PET negatif olan hastalar dikkatli takip edilmelidir. Üç cm'den küçük seminomlarda ise FDG-PET tercihe bağlıdır ve bu hastalarda kitlenin küçüldüğü veya büyümediği takip edilmelidir. Yanlış pozitiflik oranlarını azaltmak için FDG-PET son kemoterapiden 6-8 hafta sonra çekilmelidir $(3,36)$.

\section{Rezidü Doku Histolojisi}

PC-RPLND spesmenindeki histopatolojik bulgular, tedavi tercihleri ve protokolleri açısından önemlidir. NSGHT'lerde kemoterapi sonrası hastaların yaklaşık \%40-\%50'sinde nekroz, \%35-\%40'ında teratom ve \%10-\%15'inde canlı kanser oranları bildirilmektedir (37). Kurtarma kemoterapisinden sonra durum farklıdır. Canlı karsinom bulma oranı yaklaşık \%50 artar (38). IGCCCG'ye göre komplet rezeksiyon yapılmış ve spesimende \%10'dan daha az canlı hücre bulunan hastalar iyi prognoza sahip olup kemoterapi almadan izlenebilirler. Canlı kanser oranı \%10'dan fazla ise veya komplet rezeksiyon yapılamamışsa, kümülatif doz hesabı yapılarak iki kür sisplatin bazlı kemoterapi verilmelidir (39).

Toner ve ark. RPLND spesimenindeki nekroz oranlarını tespit etmede dört bağımsız prognostik faktör belirlemişlerdir. Bunlar; kitlenin 1,5 cm'den küçük olması, kitlede kemoterapi sonrası \%90 küçülme, tedavi öncesi alfa fetoprotein (AFP) ve laktat dehidrogenaz (LDH) düzeyleridir. Bu faktörlerle değerlendirildiğinde hastaların \%83'ünde nekroz tespit edilmiştir (7). Başka bir çalışmada nekrozu öngören faktörler; orşiyektomide teratom dışı tümör varlığı, kemoterapi öncesi normal belirteç düzeyleri, $20 \mathrm{~mm}$ 'den küçük rezidüel doku varlığı ve kemoterapi sonrası kitlede \%90'dan fazla radyolojik küçülme olarak belirlenmiştir (40). Rezidüel kitlelerin histolojisini öngörmek için bir çok faktör çalışıımıştır. Buna rağmen, ne bu faktörler ne de BT veya manyetik rezonans görüntüleme (MRG) gibi görüntüleme yöntemleri, bu konuda iç rahatlığıyla karar vermemize yetmemiştir $(40,41)$.

\section{Cerrahi Yaklaşım}

Kitle rezeksiyonu ve salvage cerrahiler dikkatli planlanması gereken ve teknik olarak oldukça güç ameliyatlardır. Bu işlemlerin önemi cerrahi sonrası sağkalımın doğrudan tam rezeksiyon ile ilişkili olmasına dayanmaktadır (17). Kemoterapi sonrası RPLND'de en üst düzey başarı sağlayabilmek için templatein craniyel cerrahi sınırlarının bilateral infrahiler bölge olarak tavsiye edilmektedir. Böylesine template ile bilateral infrahiler RPLND'de laterallerde üreterler, kraniyelde renal arterler, 
kaudalde aynı taraf common iliak arterin bifurkasyosu, aort ve vena cava bifurkasyosu, karşı tarafta üreterin kommon iliak damarı çaprazladığı nokta, posteriorda anterior spinal ligament ve psoas kasının fasyasıdır (42). Ancak bu yaklaşım sempatik sinirler, postganglionik sinirler ve hipogastrik pleksus hasarı nedeni ile ciddi ejakülasyon bozuklukları ile sonuçlanmaktadır. Yapılan bir araştırmada klasik bilateral RPLND'de retrograd ejakülasyon oranı \%70-\%100 arasında bulunmuştur (43).

Bunu azaltabilmek amacıyla modifiye tek taraflı RPLND tekniği gündeme gelmiştir $(44,45,46,47)$. Modifiye templateler T12L3'ten çıkan postganglionik sempatik lifleri korumak ve antegrad ejakulasyonun devamını sağlamak için inferior mezenter arterin (IMA) altında karşı taraf diseksiyonunu kısıtlar. Eğer lezyon düzgün sınırlı $5 \mathrm{~cm}$ 'den küçük ve testisin embriyolojik olarak köken aldığı bölgedeyse modifiye RPLND uygulanabilir. Ancak yüksek volümlü lezyonlarda, düzensiz sınırlı teratomlarda, alan ve lokalizasyondan bağımsız olarak modifiye sınırların dışına çıkılmalıdır (Şekil 1a) (44). Sağ taraf tümörlerinde IMA üzerindeki diseksiyon sol üretere dek genişletilmelidir (Şekil 1b) (48). Sol taraf tümörlerinde ise IMA üzerindeki diseksiyon inferior vena cavanın lateral kenarı ile sınırlanabilir (Şekil 1c). Retroaortik ve retrakaval diseksiyon her zaman yapılmalıdır $(44,49)$. Modifiye RPLND seçilmiş hastalarda güvenilir bir cerrahi olarak kabul edilebilir.

Modifiye teknikte anatomik bölgeler kısıtlanacağı için çıkarılacak lenf nodu sayısı da azalmaktadır. Ayrıca sınırların dışında \%7-\%32 oranında hastalığa rastlamak mümkündür (50). Bir çalışmada NSGHT'de PKRPLND ile çıkarılan lenf nodu sayısının prognostik önemi vurgulanmıştır. İki yıllık rekürrenssiz sağkalım, $>10,>30$ ve $>50$ lenf nodu çıkarıldığında sırasıyla \%90, $\% 95$ ve \%97 olarak ortaya konmuştur (51). Bu sonuçlar PKRPLND'de çıkartılan lenf nodu sayısının rekürrenssiz sağkalım için bağımsız prognostik rol oynadığını göstermiştir. Modifiye edilerek sınırlandıılan cerrahi alan retrograd ejakülasyon oranını düzeltebilir ancak yeterli lenf nodu çıkarımasını azaltarak patolojik evreleme ve nüks ihtimali üzerine olumsuz etkiler oluşturabilir (51).

Bir çalışmada 152 hastadan 5 cm'den küçük kitlesi olan 98'ine modifiye template rezeksiyon, diğerlerine ise bilateral klasik tam rezeksiyon yapılmıştır (44). Rekürrens oranı farklı bulunmamıştır (sırasıyla \%2 ve \%3,2). Halbuki antegrad ejakülasyon oranı sırasıyla; \%85 ve $\% 25$ olarak bulunmuştur. Bu sonuçlar bize gösteriyor ki, iyi seçilmiş hasta grubunda modifiye template rezeksiyon yapmak, rekürrens oranlarını arttırmamakta ve daha iyi antegrad ejekülasyon oranları vermektedir. Pettus ve ark. bu teknikle 130 'dan fazla hastayı değerlendirmiş ve \%79 antegrad ejakülasyon, \%98 5-yıllık nükssüzlük oranı bildirmişlerdir (52).

\section{Açık PKRPLND}

Cerrahi yaklaşım kitlenin boyutuna ve yerine göre değişim göstermelidir. Artık kitle rezeksiyonu tanımı içine giren "redo" (tekrar) retroperitoneal lenf nodu diseksiyonu ve salvage rezeksiyonları ürologlar tarafından uygulanan en zor cerrahi girişimler arasındadır. Ameliyat öncesi BT değerlendirmeleri artık kitlenin yaygınlığını genellikle olduğundan daha düşük göstermektedir $(2,53,54)$.

Literatürde infrahilar kitlelere yaklaşımda abdominal insizyonla rezeksiyon önerilmektedir (17). Bu yaklaşımın kitleye hızlı ulaşım imkanı tanıdığı belirtilmektedir. Toraksa girilmediğinden ameliyat sonrası ağıı ve pulmoner komplikasyon riski düşüktür.

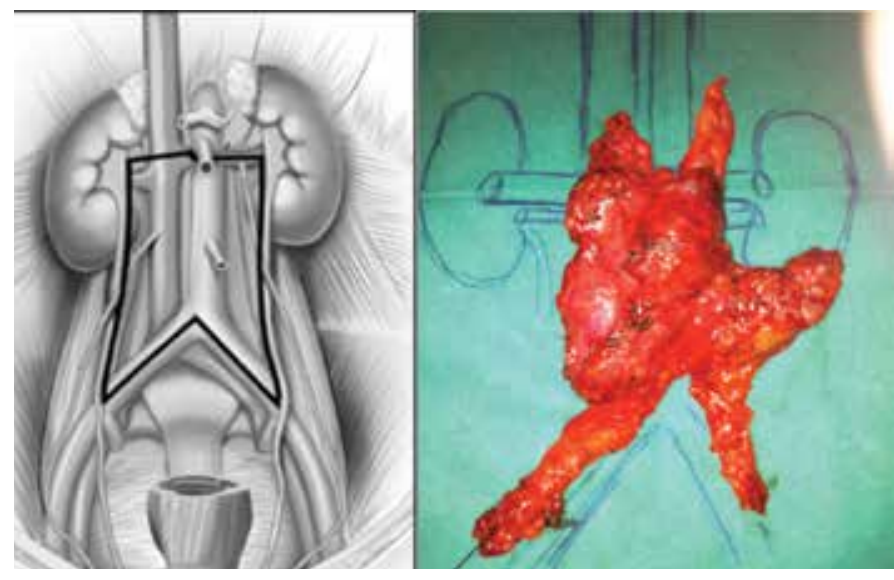

Şekil 1a. Bilateral full template RPLND

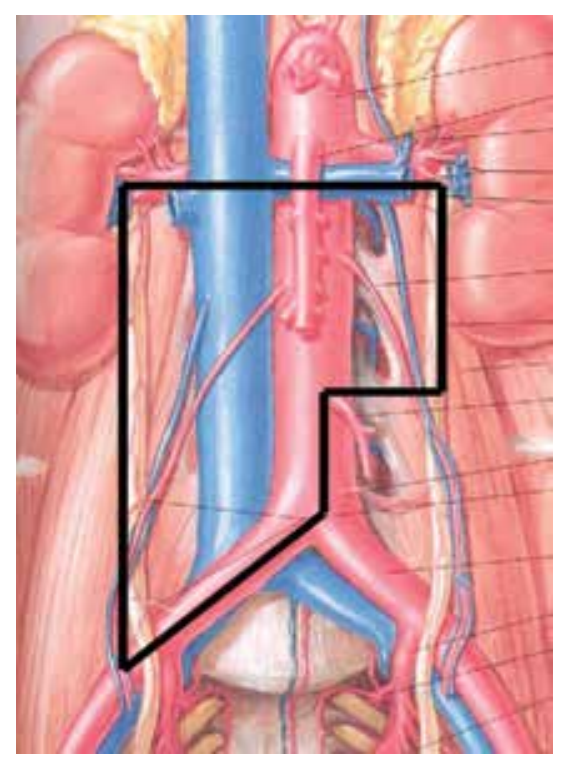

Şekil 1b. Modifiye sağ template RPLND

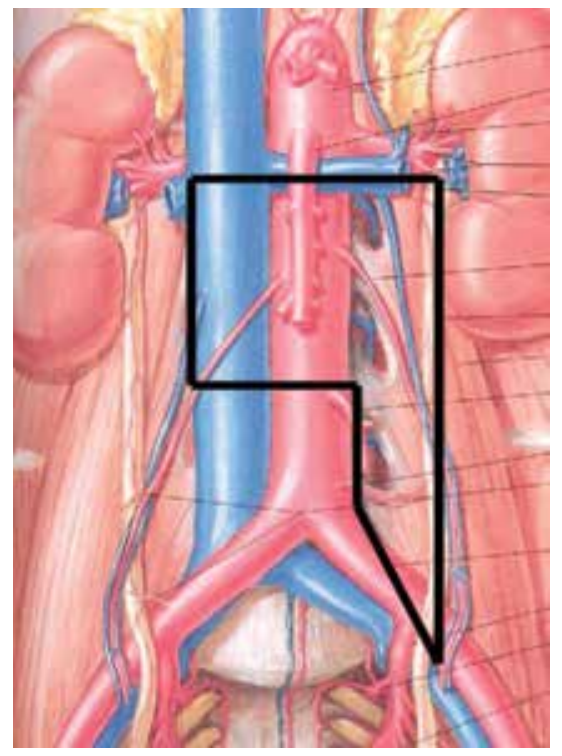

Şekil 1c. Modifiye sol template RPLND 
Bununla birlikte orta hat kesisiyle birlikte suprahilar ve retrokrural kitlelere ancak pankreas ve dalağın mobilizasyonu ile sınırlı bir yaklaşım sağlanabilir. Yine literatürde renal hilus yerleşimli büyük tümörlerin rezeksiyonu için bilateral retrokrural kitle varlığı durumunda kraniale doğru uzatılabilen Chevron kesisi önerilmektedir (17).

Literatürde intraabdominal yaklaşımın kolaylığı ve üstünlükleri vurgulanmasına rağmen, torakoabdominal yaklaşımın özel bir modifikasyonu sayesinde toraks veya batına girilmeden retroperitona hızlı ve güvenli giriş sağlanabilmektedir. Ekstraplevral extraperitoneal torakoabdominal kesi ile toraks ve peritona girmeden suprahiler ve retrokrural alanlar dahil tüm cerrahi alana geniş bir bir hakimiyet sağlanabilir. Gerektiğinde aynı insizyon kullanılarak kontralateral tarafa ulaşılabilir. İleri retrokrural tutulum ve veya ipsilateral pulmoner hastalık gösteren tek taraflı büyük kitlelerde yüksek torakoabdominal yaklaşım ile üst retroperitona iyi bir ekspozisyon sağlanarak, retroperitoneal ve infratorasik hastalık aynı seansta tedavi edilebilmektedir (55). 2012 yılında yapılan 2 çalışmada orta hat ekstraperitoneal yaklaşımda transperitonel yaklaşıma göre daha kısa ameliyat süresi, daha az kanama, daha fazla lenf nodu çıkarma ve daha erken mesane fonksiyonlarına dönüş olduğu ancak daha fazla şilöz kaçak olduğu belirtilmiştir $(56,57)$.

RPLND komplikasyonlara açık bir cerrahidir, nefrektomi, aorta veya vena kava yaralanması gibi majör sorunlara hazırlıklı olunmalıdır, şekilde vena kavaya infiltre olmuş bir tümörün rezeksiyonu sonrası greft konulmuş bir hastanın ameliyat resmi gösterilmiştir (Şekil 2).

\section{Laparoskopik-Robotik Cerrahi}

Laparoskopik PC-RPLND, az sayıda merkezde ve bazı cerrahlar tarafından yapılmaktadır. Genellikle seçilmiş, tek ve düşük tümör hacimli rezidü kitlelere yapılmaktadır. Bu nedenle morbidite, maliyet ve uzun dönem onkolojik sonuçları açık cerrahi ile başa baş tam olarak kıyaslayacak veri oluşmayabilir. Komplikasyon olarak, vasküler yaralanmalar, renal arter trombozu, hematom ve intestinal komplikasyonlar bildirilmiştir $(58,59)$. Laparoskopik PKRPLND henüz standart tedaviler içinde yer almamaktadır $(60,61)$. Robot yardımlı laparoskopik PKRPLND ile ilgili veriler ümit verici görünmekte ama henüz daha ileri yorum yapmak için yeterli değildir (62).

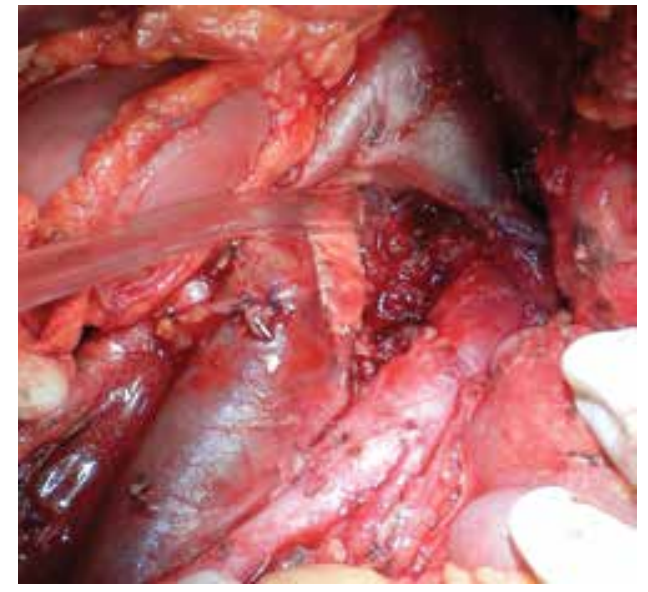

Şekil 2. Vena kava grefti
Belirteç Pozitif Olan ilk Tedaviye Yanıt Verenlerde Tedavi Metastatik hastalıkla başvuran hastaların \%70'inde, ilk basamak sisplatin bazlı kemoterapi ile hastalık tamamen gerilemekte ve radyolojik olarak kaybolmaktadır. Geri kalan \%30 hastanın yaklaşık \%10-\%15'inde tümör belirteçleri yükselmektedir $(63,64)$. Tümör belirteçleri plato yapan hastalar için uygun yaklaşım RPLND olmalıdır (33). Kistik teratomun içerdiği değişken AFP ve humankoryonik gonadotropin (HCG) seviyelerinin kana sızması yükselmiş ama stabil olan serum belirteçlerinin durumunu açıklayabilir (65). Ancak kemoterapiye başlamadan önceki HCG seviyeleri çok yüksek olan (50000'den yüksek) kötü prognozlu hastaların çoğunda kemoterapi sonunda tümör belirteçleri normale dönmez. Bu hastalar kemoterapi sonrası RPLND endikasyonu oluncaya kadar gözlenmelidir. Çünkü bu hastaların önemli bir kısmının belirteçleri zaman içinde normale dönecek ve uzun dönem normal kalacaktır. Eğer HCG tekrar yükselmeye başlarsa salvage yüksek doz kemoterapi başlamak gerekecektir (66).

Sisplatin bazlı ilk basamak kemoterapi alırken veya aldıktan hemen sonra belirteçleri yükselen, radyolojik olarak progresyon gösterilemeyen hastalarda beyin metastazı dışlanmalıdır. Bu hastalarda komplet cerrahi rezeksiyon veya yüksek doz kurtarma kemoterapisi verilebilir (65). Küratif cerrahi, hastaları yüksek doz kemoterapinin morbitesinden koruduğu gibi, tekrarlayan hastalıkta bir seçenek olarak kalmaya devam edecektir. Ameliyat öncesi tümör belirteçlerinin durumu sonucu etkilemez ancak hızlı yükselen HCG kötü prognostik faktördür ve bu hastalarda yüksek doz kurtarma kemoterapisi bir seçenek olabilir $(64,65)$.

\section{Büyüyen Teratoma Sendromu}

Kemoterapi boyunca büyüyen metastatik tümör ile normal veya normalleşen serum belirteçleri kemorezistan teratomu gösterir ve buna Büyüyen teratoma sendromu denir. Bu hastalarda salvage radyoterapi veya kemoterapi yerine, kitlenin bilateral retroperitoneal rezeksiyonu gerekir. Büyüyen teratomlar histolojik olarak benign olmalarına rağmen hızlı büyümeleri ve lokal olarak agresif ilerledikleri için mortalite ve morbiditeye yol açarlar. Bu hastalarda kemoterapi rejimi planlanan dozda tamamlanmalıdır. Büyüyen teratom sendromuna erken tanı konması ve tam rezeksiyon yapılması hastaların kür olmasını sağlar. Fakat tam rezeksiyon yapılamayan hastalarda \%83'e varan rekürrensler olmaktadır (67).

\section{Kurtarma Cerrahisi}

Salvage kemoterapinin başarısız olduğu, tam rezeke edilebilir tümörü olan hastalar, kurtarma cerrahisi adayı olabilirler. Umutsuzluk cerrahisi yapılacak hastalarda ilk IGCCCCG evresi, hastalığın evresi, AFP ve HCG seviyesi, perioperatif dönemde tümör belirteçlerinin düşük, yüksek veya stabil seyretmesi önemli prognostik faktörlerdir. Bununla birlikte tam rezeksiyon yapılan hastalarda bile uzun dönem sağ kalım \%30-\%70'dir (68).

\section{Geç Relaps}

Geç relaps başarılı primer tedaviden 2 yıl sonra gerçekleşen relaps olarak tanımlanır. Seminom ve non-seminomlu hastalarda \%3,2 ile \%1,4 arasında değişir. Retroperiton \%51,8 ile en sık karşılaşılan nüks yeridir (69). Geç relapslar hastaların \%50'sinden azında artmış tümör belirteçleri ile, bunun yanında radyolojik bulgularla ya da palpabl kitle ve sırt ağrısı gibi semptomlarla 
Çıtamak ve ark.

Kemoterapi Sonrası Retroperitoneal Lenf Nodu Diseksiyonu

\begin{tabular}{|c|c|c|c|c|c|c|c|c|}
\hline \multicolumn{5}{|l|}{ YII } & \multicolumn{4}{|l|}{ YII } \\
\hline Yöntem & 1 & 2 & $3-5$ & $6-10$ & 1 & 2 & $3-5$ & $6-10$ \\
\hline Fizik muayene & Yılda 4 kez & Yılda 4 kez & Yılda 1 kez & Yılda 1 kez & Yılda 4 kez & Yılda 4 kez & Yılda 2 kez & Yılda 1 kez \\
\hline Akciğer grafisi & Yılda 2 kez & Yılda 2 kez & & & Yılda 4 kez & Yılda 4 kez & Yılda 2 kez & Yılda 1 kez \\
\hline Abdominal $\mathrm{BT}^{\star}$ \# & Yılda 1 kez & Yılda 1 kez & & & Yılda 2 kez & Yılda 2 kez & Gerekirse & Gerekirse \\
\hline Toraks BT \#§ & & & & & Gerekirse & Gerekirse & Gerekirse & Gerekirse \\
\hline Beyin BT $\ddagger$ & & & & & Gerekirse & Gerekirse & Gerekirse & Gerekirse \\
\hline \multicolumn{9}{|c|}{ BT: Bilgisayarlı Tomografi } \\
\hline
\end{tabular}

tespit edilebilir. Cerrahi bu hastalarda en önemli tedavi yöntemidir (70). Somatik diferansiasyon gösteren teratomlarda komplet rezeksiyon yapılmalıdır, çünkü bu hastalarda salvage kemoterapinin yeri yoktur (71).

\section{Takip}

Uzun dönem takipte amaç erken dönemde relapsları belirlemektir. Diğer amaç ikincil kanser ve geç toksititeleri belirlemektir. Relaps riski evreye bağlı olup, en sık relaps tedaviden sonraki ilk 2 yılda ortaya çıkar. Tedaviden 2 yıl sonraki relaps riski \%1,4-\%3,2 arasındadır $(69,72)$.

Bu hasta grubunda takip için kanıta dayalı kesin kabul görmüş bir konsensüs bulunmamaktadır. Farklı ülke ve organizasyonlar farklı takip kılavuzları geliştirmiştir. Takip, fizik muayene ve öykü ile başlayıp tümör belirteçleri, abdomen BT (pelviste yaygın abdominal hastalıkta ve geçirilmiş inguinal cerrahiden sonra hastalı̆ı̆ın olma intimalinden dolayı pelvik BT'de eklenmelidir) ile devam eder (33). Abdominal tutulum ve tümör belirteçlerinde yükselme olmadan tek başına akciğerde hastalığın olması düşük intimal olduğu için toraks BT yerine iki yönlü akciğer grafisi önerilmektedir (73) (Tablo 1).

\section{Sonuç}

Günümüzde etkin kemoterapi ile RPLND sonrası canlı tümör oranları azalmış, \%10-\%15'e kadar düşmüş̧ür. Başarıyı arttıran bir diğer sebep ise bir çok üroloğun yapmak istemediği bu zor cerrahinin büyük merkezlerde biriken bir deneyime ve tekniğin rafine olmasına ve daha düzgün hasta takip protokollerinin oluşmasına sebep olmasındandır. Tümör hacmi daha düşük olan hastalarda modifiye rezeksiyon ve sinir koruma tekniği, daha az komplikasyon ve daha iyi hayat kalitesi hedefine ulaşmada kritiktir. Daha geniş diseksiyon ve daha çok lenf nodu ile, daha az rekürrense sebep olunacağı unutulmamalıdır. Bu sebeple cerrahi sınırları belirlemede tümörün boyutu ve yerleşimi yanında relaps riski, cerrahın deneyim ve tercihleri ve hastanın yaşam kalitesi beklentilerini de içine alan bir çok faktör belirleyici olacaktır. Canlı tümör varlığı durumunda komplet rezeksiyona sebep olan bir cerrahi, ameliyat sonrası kemoterapi vermekten her zaman çok daha iyi sonuç verecektir. Çok iyi bir sağkalım beklentisi vaat eden testis tümörlerinde, özellikle hastaların genç ve fertilite beklentisi içinde oldukları da düşünüldüğünde, onkolojik cerrahi felsefeyi titizlikle özümseyerek uygulamanın son derece kıymetli olduğu apaçık ortadadır.

Çıkar çatışması: Yazarlar bu makale ile ilgili olarak herhangi bir çıkar çatışması bildirmemişlerdir.

\section{Kaynaklar}

1. Jemal A, Murray T, Samuels A, et al. Cancer statistics, 2003. CA Cancer J Clin 2003;53:5-26.

2. Comisarow RH, Grabstald $\mathrm{H}$. Re-exploration for retroperitoneal lymph node metastases from testis tumors. J Urol 1976;115:569-571.

3. Albers P, Albrecht W, Algaba F, et al. EAU guidelines on testicular cancer: 2011 update. Eur Urol 2011;60:304-319.

4. Krege S, Beyer J, Souchon R, et al. European Consensus Conference on Diagnosis and Treatment of Germ Cell Cancer: A Report of the Second Meeting of the European Germ Cell Cancer Consensus Group (EGCCCG): Part II. Eur Urol 2008;53:497-513.

5. Schmoll HJ, Jordan K, Huddart R, et al. Testicular non-seminoma: ESMO clinical practice guidelines for diagnosis, treatment and follow-up. Ann Oncol 2010;21:147-154.

6. Motzer RJ, Bolger GB, Boston B, et al. Testicular cancer. Clinical practice guidelines in oncology. I Natl Compr Cancer Netw 2006;4:1038-1058.

7. Toner GC, Panicek DM, Heelan RT, et al. Adjunctive surgery after chemotherapy for nonseminomatous germ cell tumors: recommendations for patient selection. J Clin Oncol 1990;8:1683-1694.

8. Schmoll HJ, Souchon R, Krege S, et al. European consensus on diagnosis and treatment of germ cell cancer: a report of the European Germ Cell Cancer Consensus Group (EGCCCG). Ann Oncol 2004;15:1377-1399.

9. Fossa SD, Ous S, Lien HH, Stenwig AE. Post-chemotherapy lymph node histology in radiologically normal patients with metastatic nonseminomatous testicular cancer. J Urol 1989;141:557-559.

10. Ehrlich Y, Brames MJ, Beck SD, et al. Long-term follow-up of cisplatin combination chemotherapy in patients with disseminated 
nonseminomatous germ cell tumors: is a postchemotherapy retroperitoneal lymph node dissection needed after complete remission? J Clin Oncol 2010;28:531-536.

11. Kollmannsberger C, Daneshmand S, So A, et al. Management of disseminated nonseminomatous germ cell tumors with risk-based chemotherapy followed by response-guided postchemotherapy surgery. J Clin Oncol 2010;28:537-542.

12. Tarin T, Carver B, Sheinfeld J. The role of lymphadenectomy for testicular cancer: indications, controversies, and complications. Urol Clin North Am 2011;38:439-449.

13. Oldenburg J, Alfsen GC, Lien $\mathrm{HH}$, et al. Postchemotherapy retroperitoneal surgery remains necessary in patients with nonseminomatous testicular cancer and minimal residual tumor masses. J Clin Oncol 2003;21:3310-3317.

14. Logothetis C), Samuels ML, Trindade A, et al. The growing teratoma syndrome. Cancer 1982;50:1629-1635.

15. Krege S, Beyer J, Souchon R, et al. European Consensus Conference on Diagnosis and Treatment of Germ Cell Cancer: a report of the second meeting of the European Germ Cell Cancer Consensus Group (EGCCCG). I Eur Urol 2008;53:478-496.

16. Kakiashvili DA-CL, Moore M. Post-chemotherapy retroperitoneal lymph node dissection for testicular germ cell tumors: is surgery indicated in all patients and is bilateral template necessary? Princess Margaret Hospital experience. J Urol 2009;181:325.

17. Albers P, Melchior D, Müller SC. Surgery in metastatic testicular cancer. Eur Urol 2003;44:233-244.

18. Fossa SD, Borge L, Aass N, et al. The treatment of advanced metastatic seminoma: experience in 55 cases. J Clin Oncol 1987;5:1071-1077.

19. Herr HW, BosI G. Residual mass after after chemotherapy for seminoma: changing concepts of management. J Urol 1987;137:1234-1235.

20. Hofmockel G, Gruss A, Theiss M. Chemotherapy in advanced seminoma and the role of postcytostatic retroperitoneal lymph node dissection. Urol Int 1996;57:38-42.

21. Kamat MR, Kulkarni JN, Tongoankar HB, et al. Value of retroperitoneal lymph node dissection in advanced testicular seminoma. J Surg Oncol 1992;51:65-67.

22. Loehrer PJ Sr, Birch R, Williams SD, et al. Chemotherapy of metastatic seminoma: the Southeastern Cancer Study Group experience. J Clin Oncol 1987;5:1212-1220.

23. Motzer R, Bosl G, Heelan R, et al. Residual mass: an indication for further therapy in patients with advanced seminoma following systemic chemotherapy. J Clin Oncol 1987;5:1064-1070.

24. Peckham MJ, Horwich A, Hendry WF. Advanced seminoma treatment with cisplatinum based combination chemotherapy or carboplatin (JM8). Br J Cancer 1985;52:7-13.

25. De Santis M, Becherer A, Bokemeyer C, et al. 2-18 fluoro-deoxy-Dglucose positron emission tomography is a reliable predictor for viable tumor in postchemotherapy seminoma: an update of the prospective multicentric SEMPET trial. J Clin Oncol 2004;22:1034-1039.

26. Flechon A, Bompas E, Biron P, et al. Management of postchemotherapy residual masses in advanced seminoma. J Urol 1979;168:1975-1979.

27. Friedman EL, Garnick MB, Stomper PC, et al. Therapeutic guidelines and results in advanced seminoma. J Clin Oncol 1985;3:1325-1332.

28. Schultz SM, Einhorn LH, Conces DJ, et al. Management of postchemotherapy residual mass in patients with advanced seminoma: Indiana University experience. J Clin Oncol 1989;7:1497-503.

29. Ravi R, Rao RR, Shanta V. Integrated approach to the management of patients with advanced germ cell tumors of the testis. J Surg Oncol 1994;55:47-51.

30. Puc HS, Heelan R, Mazumdar M, et al. Management of residual mass in advanced seminoma: results and recommendations from the Memorial Sloan Kettering Cancer Center. J Clin Oncol 1996;14:454-460.
31. Mosharafa AA, Foster RS, Leibovich CC, et al. Is post-chemotherapy resection of seminomatous elements associated with higher acute morbidity? J Urol 2003;169:2126-2128.

32. Pfannenberg AC, Oechsle $K$, Bokemeyer $C$, et al. The role of $[(18)$ F] FDG-PET, CT/MRI and tumor marker kinetics in the evaluation of post chemotherapy residual masses in metastatic germ cell tumorsprospects for management. World J Urol 2004;22:132-139.

33. Daneshmand S, Albers P, Fossa SD, et al. Contemporary management of postchemotherapy testis cancer. Eur Urol 2012;62:867-876.

34. Bachner M, Loriot Y, Gross-Goupil M, et al. 2-18fluoro-deoxy-Dglucose positron emission tomography (FDG-PET) for postchemotherapy seminoma residual lesions: a retrospective validation of the SEMPET trial. Ann Oncol 2012;23:59-64.

35. Herr HW, Sheinfeld J, Puc HS, et al. Surgery for a post-chemotherapy residual mass in seminoma. J Urol 1997;157:860-862.

36. Wood L, Kollmannsberger $C$, Jewett $M$, et al. Canadian consensus guidelines for the management of testicular germ cell cancer. Can Urol Assoc J 2010;4:19-38.

37. Sheinfeld J, Bartsch G, Bosl G). Surgery of Testicular Tumors. In: Wein A), Kavoussi LR, Novick AC, Partin AW, Peters CA, eds. CampbellWalsh Urology. Vol 1. 9 ed. Philadelphia: WB Saunders 2007:945.

38. Fox EP, Weathers TD, Williams SD, et al. Outcome analysis for patients with persistent nonteratomatous germ cell tumor in postchemotherapy retroperitoneal lymph node dissections. J Clin Oncol 1993;11:1294-1299.

39. Fizazi K, Tjulandin S, Salvioni R, et al. Viable malignant cells after primary chemotherapy for disseminated nonseminomatous germ cell tumors: prognostic factors and role of postsurgery chemotherapy-results from an international study group. J Clin Oncol 2001;19:2647-2657.

40. Steyerberg EW, Keizer HJ, Fossa SD, et al. Prediction of residual retroperitoneal mass histology after chemotherapy for metastatic nonseminomatous germ cell tumor: multivariate analysis of individual patient data from six study groups. J Clin Oncol 1995;13:1177-1187.

41. Albers P, Weissbach L, Krege S, et al. Prediction of necrosis after chemotherapy of advanced germ cell tumors: results of a prospective multicenter trial of the German Testicular Cancer Study Group. J Urol 2004; 171:1835-1838.

42. Stephenson AJ, Gilligan TD. Neoplasms of the testis. In Campbell-Walsh Urology, 10th Edition, Philadelphia:Elsevier Saunders;2012:874-881.

43. Donohue JP, Rowland RG. Complications of retroperitoneal lymph node dissection. J Urol 1981;125:338-340.

44. Heidenreich A, Pfister D, Witthuhn R, et al. Postchemotherapy retroperitoneal lymph node dissection in advanced testicular cancer: radical or modified template resection. Eur Urol 2009;55:217-226.

45. Wood DP Jr, Herr HW, Heller G, et al. Distribution of retroperitoneal metastases after chemotherapy in patients with nonseminomatous germ cell tumors. J Urol 1992;148:1812-1815.

46. Ateş F, Yılmaz Ö, Baykal KV. Testis tümöründe kemoterapi sonrası kitlelere yaklaşım ve cerrahi teknik. Üroonkoloji bülteni 2011:68-74.

47. Beck SD, Foster RS, Bihrle R, et al. Is full bilateral retroperitoneal lymph node dissection always necessary for postchemotherapy residual tumor? Cancer 2007;110:1235-1240.

48. Colleselli K, Poisel S, Schachtner W, et al. Nerve-preserving bilateral retroperitoneal lymphadenectomy: anatomical study and operative approach. J Urol 1990;144:293-297.

49. Soydan H, Baykal KV. Sinir koruyucu RPLND: teknik. Üroonkoloji bülteni 2012:185-189.

50. Carver BS, Shayegan B, Eggener S, et al. Incidence of metastatic nonseminomatous germ cell tumor outside the boundaries of a modified postchemotherapy retroperitoneal lymph node dissection. J Clin Oncol 2007;25:4365-4369. 
51. Carver BS, Cronin AM, Eggener $S$, et al. The total number of retroperitoneal lymph nodes resected impacts clinical outcome after chemotherapy for metastatic testicular cancer. Urology 2010;75:1431-1435.

52. Pettus JA, Carver BS, Masterson T, et al. Preservation of ejaculation in patients undergoing nerve-sparing postchemotherapy retroperitoneal lymph node dissection for metastatic testicular cancer. Urology 2009;73:328-331.

53. Gualdi GF, Petta S, Liberti M, et al. Radiologic staging after surgical, chemical, and radiation treatment of non-seminomatous tumors of the testis. Archivio italiano di urologia, andrologia: organo ufficiale [di] Societa italiana di ecografia urologica e nefrologica/Associazione ricerche in urologia 1997;69:9-14.

54. Hilton S, Herr $\mathrm{H}$, Teitcher JB, et al. CT detection of retroperitoneal lymph node metastases in patients with clinical stage I testicular nonseminomatous germ cell cancer: assessment of size and distribution criteria. American journal of roentgenology 1997; 169:521-525.

55. Önol Y, Önol F. Metastatik testis tümörlerinde kemoterapi sonrası artık kitle rezeksiyonu. In: Özen H, Türkeri L. Üroonkoloji, Ankara, Üroonkoloji Derneği;2007:1143-1152.

56. Kim P, Syan-Bhanvadia S, Djaladat H, et al. Midline extraperitoneal approach for retroperitoneal lymph node dissection for testicular germ cell tumor. Urology 2012;80:941-945.

57. Arai $Y$, Kaiho $Y$, Yamada $S$, et al. Extraperitoneal laparoscopic retroperitoneal lymph node dissection after chemotherapy for nonseminomatous testicular germ-cell tumor: surgical and oncological outcomes. International urology and nephrology, 2012;44:1389-1395.

58. Calestroupat JP, Sanchez-Salas R, Cathelineau X, et al. Postchemotherapy laparoscopic retroperitoneal lymph node dissection in nonseminomatous germ-cell tumor. J Endourol 2009;23:645-650.

59. Albers P. Surgery in testis cancer: laparoscopic and open techniques. Curr Opin Urol 2002;12:435-440.

60. Aufderklamm S, Todenhöfer T, Hennenlotter J, et al. Bilateral laparoscopic postchemotherapy retroperitoneal lymph-node dissection in nonseminomatous germ cell tumors-a comparison to template dissection. J Endourol 2013;27:856-861.
61. Busch J, Magheli A, Erber B, et al. (2012). Laparoscopic and open postchemotherapy retroperitoneal lymph node dissection in patients with advanced testicular cancer-a single center analysis. BMC urology 2012;12:15.

62. Dogra PN, Singh P, Saini AK, et al. Robot assisted laparoscopic retroperitoneal lymph node dissection in testicular tumor. Urology annals 2013;5:223.

63. Beck SD, Foster RS, Bihrle R, et al. Outcome analysis for patients with elevated serum tumor markers at postchemotherapy retroperitoneal lymph node dissection. J Clin Oncol 2005;23:6149-6156.

64. Ong TA, Winkler MH, Savage PM, et al. Retroperitoneal lymph node dissection after chemotherapy in patients with elevated tumour markers: indications, histopathology and outcome. BJU Int 2008; 102:198-202.

65. Beck SD, Foster RS, Bihrle R, et al. Post chemotherapy RPLND in patients with elevated markers: current concepts and clinical outcome. Urol Clin North Am 2007;34:219-225.

66. Zon RT, Nichols C, Einhorn LH. Management strategies and outcomes of germ cell tumor patients with very high human chorionic gonadotropin levels. J Clin Oncol 1998;16:1294-1297.

67. Carver BS, Sheinfeld J. Management of post-chemotherapy extraretroperitoneal residual masses. World J Urol 2009;27:489-492.

68. Heidenreich A, Thuer D, Polyakov S. Postchemotherapy retroperitoneal lymph node dissection in advanced germ cell tumours of the testis. Eur Urol 2008;53:260-274.

69. Oldenburg J, Martin JM, Fossa SD. Late relapses of germ cell malignancies: incidence, management, and prognosis. J Clin Oncol 2006;24:5503-5511.

70. Sharp DS, Carver BS, Eggener SE, et al. Clinical outcome and predictors of survival in late relapse of germ cell tumor. J Clin Oncol 2008;26:5524-5529.

71. Lutke Holzik MF, Hoekstra HJ, Mulder NH, et al. Non-germ cell malignancy in residual or recurrent mass after chemotherapy for nonseminomatous testicular germ cell tumor. Ann Surg Oncol 2003;10:131-135.

72. Ronnen EA, Kondagunta GV, Bacik J, et al. Incidence of late-relapse germ cell tumor and outcome to salvage chemotherapy. J Clin Oncol 2005;23:6999-7004.

73. van As NJ, Gilbert DC, Money-Kyrle J, et al. Evidence-based pragmatic guidelines for the follow-up of testicular cancer: optimising the detection of relapse. Br J Cancer 2008;98:1894-1902. 